\title{
A AULA DE INGLÊS \\ E O DESMONTE DA EDUCAÇÃO COMO PRÁXIS POLÍTICA: \\ UM PROJETO DE ALIENAÇÃO DO SUJEITO SOCIAL
}

Davi Gonçalves*

RESUMO: Essa proposta de trabalho visa refletir acerca de questões educacionais em paralelo com a práxis social. Mais especificamente, a ideia é discutir as características e implicações da realidade e prática social dos alunos da escola pública levando em consideração anseios contemporâneos pautados no tema. Os dados analisados foram coletados em uma escola pública situada na cidade de Maringá-PR, no ano de 2009, durante o estágio curricular supervisionado obrigatório de observação - tanto do entorno escolar quanto das aulas. Com enfoque nesse aspecto mais social das práticas educacionais escolares, o principal arcabouço teórico para análise dos dados é aquele oferecido por István Mészáros no livro $A$ educação para além do capital (2008). Os resultados, não-conclusivos, apontam para um cenário alarmante: se na esfera privada já há tempos a educação se tornou uma mercadoria e os alunos meros clientes, a esfera pública tem sido redirecionada para caminhos análogos, em diversos sentidos.

PALAVRAS-CHAVE: Relato de experiência. Marx. Escola pública.

\footnotetext{
* Doutor em Teoria, Crítica e História da Tradução pela Universidade Federal de Santa Catarina (Ufsc). Professor de Literaturas de Língua Inglesa do Departamento de Letras da Universidade Estadual do Centro-Oeste (Unicentro/ PR).
} 


\section{Introdução: "uma alternativa educacional significativamente diferente"}

Pode-se considerar senso comum a ideia questionável de que, por excelência e em sua grande maioria, as escolas privadas possuem, no Brasil, uma estrutura física e pedagógica diferenciada em comparação com as públicas. Com propagandas diferenciadas e mensalidades a cada dia mais caras, as comparações sempre foram inevitáveis, principalmente no quesito qualidade. Entretanto, em um país que diariamente depreda sem receio a educação de ambos setores, esse dualismo chama a atenção: será mesmo que existe tamanha diferença? E, se for o caso, de que forma ela se tornou institucionalizada e quais suas implicações sociais? Além disso, é válido ressaltar que parecem constantes também muitos aspectos problemáticos na maneira privatista de se pensar a educação, que, longe de representar qualquer tipo de solução, estaria mais para um sintoma e/ou exponencial dessa crise. Partindo disso, minha hipótese é a de que essa fronteira separando educação pública e privada foi sempre turva, já que nossas relações sociais são constituídas como um todo, dentro e fora das paredes das escolas - ou seja, são também nossos discursos, práticas e atividades intersociais que estruturam o próprio ambiente que julgamos nos condicionar.

$\mathrm{O}$ interesse em escrever esse trabalho se deu durante minha experiência de observação de aulas e entorno escolar, como parte do estágio curricular supervisionado de minha graduação. Nele, puder perceber uma presença considerável de alunos de classe média e até classe média alta em uma escola pública dentre as mais periféricas da cidade. De onde olhava, a impressão que tinha era que aqueles sujeitos estavam ali não por julgarem aquela escola um ambiente rico em aprendizado, mas por seus familiares verem pouca diferença entre o âmbito público e o privado como um todo para os fins que precisavam - com exceção das mensalidades, obviamente. Em Maringá-PR, duas escolas públicas estão, é fato, dentre as (consideradas) melhores da cidade, o que não é o caso desta onde o estágio foi realizado. Estas duas, de muito mais renome, se encontram todos os anos em sua capacidade máxima talvez não somente por não darem conta da demanda, mas também porque os indivíduos que costumavam frequentar intuições privadas ultimamente têm migrado para este ambiente que antigamente era desconhecido por eles - seja pela crise atual, que 
tem dirimido a autonomia financeira da população, ou pelo desgaste educacional de ambos os setores.

Entretanto, diferenças extremas entre classes também acarretam em diferenças extremas de relações/práticas sociais. Sendo assim, se a relação entre os colegas de classe não for bem trabalhada, a interação entre eles (quando representantes de duas classes sociais muito divergentes) pode acabar se tornando prejudicial e dificultar o aprendizado dos mesmos, em função disso. É no sentido de evidenciar o ponto chave das consequências dessa interação, ou seja, da presença de uma distinta gama social de estudantes na rede pública explorando essa nova realidade e coexistindo com uma classe (mal) acostumada com hierarquias sociais, que cito a experiência vivida durante o estágio. Fatos lá observados mostram o quanto estas instituições ainda estão incapacitadas de intermediar questões relacionadas ao cunho das interações sociais, tão complexas e significativas para o aprendizado. Que os alunos mais favorecidos financeiramente não costumavam, há poucos anos, ocupar salas de aula das escolas públicas, pode-se inferir. Porém, agora, frente à essa nova condição ocasionada principalmente por uma crise geral no ensino como um todo, cabe a nós compreender tal questão e explorar suas potencialidades, repensando a suposta ambivalência entre ensino público e privado buscando possíveis medidas para potencializar uma discussão sobre o capital dentro da escola. Isto dado que:

Quanto aos seus parâmetros estruturais fundamentais o capital deve permanecer sempre incontestável, mesmo que todos os tipos de corretivos marginais sejam não só compatíveis, mas também benéficos, e realmente necessários, para ele importando a sobrevivência continuada do sistema. Limitar uma mudança educacional radical às margens corretivas interesseiras do capital significa abandonar de uma só vez, conscientemente ou não, o objetivo de uma transformação social qualitativa. Do mesmo modo, procurar margens de reforma sistemática no próprio enquadramento do sistema capitalista é uma contradição em termos. É por isso que é necessário romper com a lógica do capital se quisermos contemplar a criação de uma alternativa educacional significativamente diferente. (MÉSZÁROS, 2008, p. 26) 
Resolvemos abordar tal aspecto porque vemos nos interesses do capital um grande empecilho ao ensino de qualidade - interesses esses trazidos cada vez mais por alunos advindos de classes sociais favorecidas, reproduzindo um discurso e prática consumista e materialista (não no materialismo de Marx, mas em seu sentido popularizado). Obviamente não há nem deveria haver nenhuma lei que vete o ingresso de estudantes de classes mais favorecidas dentro de instituições públicas, mas no caso dos colégios a falta de tato para lidar com essa diferença pode causar efeito contrário do desejado - aumentando o preconceito social ao invés de mitigando-o. Deparado com a problemática advinda de tal situação, da coexistência desses dois "tipos" de alunos dentro da sala de aula (vendo, em um colégio público um grande número de celulares modernos, MP3 e Ipod em salas de aula, carros importados em posse dos pais dos alunos e até mesmo a sua renda mensal) senti a necessidade de articular esta reflexão, já que os fatos trazidos fizeram com que meu interesse e curiosidade fossem despertados. O objetivo geral deste estudo, neste sentido, é investigar essa realidade e constructo social de algumas famílias cujos filhos foram encaminhados para escolas públicas. Como objetivos específicos visa-se elucidar em que implicam os dados coletados e analisados nos questionários encaminhados às famílias dos alunos e aos professores. Contempladas no questionário, é possível refletir acerca de algumas das consequências desta miscigenação social dentro das escolas públicas como, por exemplo, suas vantagens e desvantagens. Será que os alunos têm se tornado mais tolerantes com relação a diferença? Ou mais suscetíveis a ridicularizarem seus colegas com condições sociais menos privilegiadas?

Como meio de alcançar os objetivos almejados, já apontei, é desenvolvida uma pesquisa de cunho qualitativo e também quantitativo. A coleta de dados é efetuada a partir de um questionário respondido por educadores, educandos e pais ou responsáveis - isto no âmbito escolar tanto de instituições privadas quanto públicas. Neste questionário busco compreender a fundo os pensamentos destes três diferentes perfis, analisando e comparando suas respostas, principalmente com relação ao ensino público e particular. Desse modo, é estabelecido um paralelo entre as razões, fundamentos, justificativas que encontrei 
e uma reflexão proposta a partir destes resultados. O questionário, trazido como anexo, foi desenvolvido por mim e distribuído nas salas de aula da escola na qual o estágio foi realizado, sendo também oferecido na portaria de outras instituições. Além dos dados aqui expostos, durante o estágio também foram requisitadas informações que o núcleo administrativo destas escolas já possui, como por exemplo os dados relativos ao perfil de cada família dos alunos. Com enfoque nesse aspecto mais social das práticas educacionais escolares, o principal arcabouço teórico para análise dos dados é aquele oferecido por István Mészáros no livro A educação para além do capital (2008). Além dele, quatro outros textos que abordam questões essenciais relacionadas ao ensino público e particular foram selecionados. Serão eles sucintamente contextualizados na parte final da análise - após minha exposição e análise dos dados coletados - para que suas contribuições sejam posteriormente correlacionadas com o objetivo de se articular uma proposta reflexiva com uma base de maior sustento, e logo de maneira mais clara e eficiente.

\section{O questionário}

Segue questionário encaminhado aos professores, pais/responsáveis e alunos:

Pais: 1. A maior parte da vida escolar do(s) seu(s) filho(s) se deu em: a) escola pública; b) escola; c) escola particular. Por quê? a) questão financeira; b) qualidade de ensino; c) segurança; d) outros. 2. Em sua opinião, qual a maior diferença entre as escolas públicas e particulares? a) capacitação dos professores; b) mentalidade dos alunos; c) infraestrutura; d) status; e) qualidade das aulas; f) segurança; g) outros. 3. Qual é a sua prioridade com relação aos gastos familiares? a) segurança; b) conforto; c) educação dos filhos; d) lazer; e) planejamento; f) outros. 4. Quem você pensa ser o maior culpado pelo baixo nível educacional no país: a) professores; b) pais; c) alunos; d) governo.

Professores: 1 . Em qual destes dois ambientes você acredita ser mais agradável lecionar: a) escola pública; b) escola particular; Por quê? a) questão financeira; b) segurança; c) estabilidade; d) comportamento dos alunos; e) outros. 2. Em sua opinião, qual a maior diferença entre as escolas públicas e particulares? a) capacitação dos professores; 
b) mentalidade dos alunos; c) infraestrutura; d) relação entre os funcionários; e) material didático; f) segurança; g) outros. 3. Quem você pensa ser o maior culpado pelo baixo nível educacional no país: a) professores; b) pais; c) alunos; d) governo.

Alunos: A maior parte de sua vida escolar se deu em: a) escola pública; b) escola; c) escola particular. 2. Em sua opinião, qual a maior diferença entre as escolas públicas e particulares? a) capacitação dos professores; b) mentalidade dos alunos; c) infraestrutura; d) status; e) qualidade das aulas; f) segurança; g) outros. 3. Quem você pensa ser o maior culpado pelo baixo nível educacional no país: a) professores; b) pais; c) alunos; d) governo.

Abaixo apresento os resultados da coleta de dados referentes aos questionários, feito a partir de inquietações tendo em vista minhas dúvidas sobre a situação contextual dos alunos ali presentes - já esboçadas anteriormente. O questionário foi respondido por 20 professores, divididos entre escola pública e privada. No primeiro questionamento colocado percebe-se que: 45\% dos professores responderam que lecionar em escola pública seria preferível principalmente pela estabilidade em que tal emprego implica. 25\%, por outro lado, optaram pela escola particular em função da sua segurança. É interessante notar que somente $15 \%$ cita crer em alguma diferença entre o comportamento dos alunos em ambas as instituições, e que apenas outros $15 \%$ pensam em outras razões maiores do que as pré-dispostas. Quanto aos 50 pais de alunos presentes nas duas esferas do ensino notase que mesmo aqueles que têm seus filhos nas escolas privadas, em sua maioria, responderam que as diferenças maiores para eles entre essas duas realidades educacionais estão na infraestrutura ou na segurança das escolas - 36\% para cada lado. Ou seja, eles não acreditam que de fato a qualidade do ensino por si só é, de forma geral, superior. Da mesma forma, 14\% informaram que a principal distinção não passava da questão do status, e outros $14 \%$ alegaram a capacitação profissional.

Outro dado que é importante analisar é quanto às prioridades com relação aos gastos familiares: 38\% dos pais - a maioria - admitiram que hoje o "planejamento" é o 
principal, e a educação empata com o conforto, nesse quesito - $24 \%$ de votos para cada uma. Apenas 14\% disseram ter feito a escolha preocupados com a questão da segurança. Pode-se perceber, logo, que o planejamento para os pais é algo prioritariamente preocupante, enquanto a educação se iguala ao conforto, em importância, quando se tem em vista a questão financeira. Algo interessante a respeito do ponto-de-vista dos 50 alunos da rede pública e privada é ver que dentre todos eles - mas principalmente entre aqueles que já estudaram em ambas - a escolha que prevaleceu como possível maior diferença entre as escolas públicas e privadas foi a "mentalidade dos alunos". 46\% admite que na escola privada os alunos têm preocupações muitas vezes claras com o vestibular, temem reprovar e possuem outras preocupações relacionadas - superficiais, mas o suficiente para que o seu aprendizado seja um pouco mais concreto - enquanto acredita que na escola pública o que o professor traz dificilmente é levado a sério, já que as preocupações e pensamentos dos alunos parecem estar, na maior parte das vezes, fora das salas de aula. $24 \%$ indica a infraestrutura como maior diferença, e outros $24 \%$ a capacitação dos professores - enquanto apenas $6 \%$ indicaram a questão do status, questão essa pouco assinalada durante os preenchimentos em geral.

Ora, para se falar sobre qualquer aspecto da escola particular ou da escola pública, bem como refletir acerca daquilo que tais dados podem indicar, precisamos entender que o professor não é respeitado dentro de sala de aula, que seu trabalho não é valorizado, que o aluno não se sente interessado, que o conteúdo não é devidamente trabalhado, que a escola particular não se salva com relação a nada disso e que muitos desses fatos não acontecem por acaso. O governo não precisa de um ensino público ou privado que seja decente. O que ele precisa é de votos, e é o que essa formação superficial e de cunho manipulador produz de melhor: votos. A escola, hoje equiparável a representação de uma farsa social, evidencia que aquilo que ela possui de mais revolucionário está sendo dificultado por questões de cunho administrativo e social de uma forma que acaba deixando os cidadãos com os valores completamente prejudicados. Professores a procuram pela estabilidade, pais e responsáveis para reduzir os gastos familiares, e apenas os alunos veem na mentalidade 
propagada no ambiente como vantajoso - mas nenhum dos três grupos foram capazes de apontar outras razões e/ou possibilidades para ela. A importância disso muito bem indica Mészáros (2008, p. 50) ao advogar em favor de uma ideia menos limitada de educação:

\begin{abstract}
Nunca é demasiado sublinhar a importância estratégica da concepção mais ampla de educação, expressa na frase: "a aprendizagem é a nossa própria vida". Pois muito do nosso processo continuado de aprendizagem se situa, felizmente, fora das instituições educacionais formais. Felizmente, porque esses processos não podem ser prontamente manipulados e controlados pela estrutura educacional formal legalmente salvaguardada e sancionada. Eles comportam tudo, desde o brotar das nossas respostas críticas relativamente aos ambientes materiais mais ou menos desprovidos na nossa infância, assim como o nosso primeiro encontro com poesia e a arte, até às nossas diversas experiências de trabalho, sujeitas a um escrutínio equilibrado por nós próprios e pelas pessoas com quem as partilhamos, e, claro, até ao nosso envolvimento de muitas maneiras diferentes em conflitos e confrontos durante a nossa vida, incluindo as disputas morais, políticas e sociais dos nossos dias. (MÉSZÁROS, 2008, p. 50)
\end{abstract}

Que da escola pública sai um grande número de cidadãos talvez não tão bem instruídos quanto o desejado, isso nunca foi novidade. Mas será que a formação da escola particular é assim tão diferente? É isso que vale a pena investigar. O que é um país sem educação de qualidade? Um país sem uma educação de qualidade é um país sem valores, sem moral, sem estrutura, sem base, sem renovação, sem razão de ser. É um país sem futuro, e é para esse lado que estamos caminhando, caso essas questões não sejam levadas a sério. Tudo isso trazido e citado anteriormente não é mais surpresa para nenhum possível leitor; é um senso comum, praticamente, assumir que as escolas brasileiras não correspondem com a necessidade real dos brasileiros - que inserimos nelas outras ansiedades, que buscamos nelas outros valores e que tenhamos nos acostumado com tão pouco. Mesmo porque poucos sabem, de fato, o que essa "necessidade real" seria. A queda de qualidade das escolas privadas, se for comprovada - conforme as contribuições teóricas que seguem - traz uma importante questão à tona. Até quando será que os pais estarão dispos- 
tos a pagar caro por um ensino que não corresponde às expectativas? Ora, a situação financeira da população brasileira em geral não é das melhores e a administração por ela neste quesito é feita, muitas vezes, da forma mais "consciente" possível com o intuito de se evitarem gastos "desnecessários" - o problema é justamente a fronteira que separa o necessário do desnecessário.

Se a sociedade já vem sendo ensinada a não dar valor para a educação, de uma forma geral, nada mais natural do que, aos poucos, ela começar a considerar fazer menos "sacrifícios” em função dela. Percebendo qual o real cenário a respeito da educação pública e particular brasileira, muitos de nós podemos passar a achar que aquilo que valia a pena, de repente, não vale mais - o que é até bastante justificável. As prioridades começam a mudar, na sociedade contemporânea, as famílias possuem centenas de preocupações além da educação dos filhos. Como: conforto, segurança, lazer... E de repente a educação já não faz tanta diferença, afinal o que importa é "passar no vestibular", e para isso posso gastar apenas no ensino médio - ou senão existem aqueles cursinhos de um semestre que são capazes de dar o suporte necessário para isso. Qual é o sentido de se gastar por anos com uma educação pífia se você pode gastar por meses menos que um oitavo disso, e não perder em praticamente nada? Talvez ainda exista muita gente que se sente confusa ao se deparar com esse tipo de questionamento, mas é tudo uma questão de tempo, e se as coisas continuarem como estão logo ver uma sala de escola pública com alunos de classe média alta também vai virar senso comum. Direito deles, e de todos - só é uma cena que, particularmente, eu gostaria de registrar em um outro contexto.

A verdade é que isso já vem acontecendo, e de uma forma bastante consistente. Os professores das escolas públicas estão ministrando aulas para alunos de realidades sociais completamente opostas, e este fato aparentemente sem consequências acarreta em sérias questões relativas à convívios sociais que são muito mais complexas do que se possa imaginar. Toda a ação causa uma reação, e todo o choque cultural é impactante e consequentemente resulta numa resposta que muitas vezes não é muito positiva, se não for propriamente trabalhada - seja entre professores, alunos, famílias. É evidente que as escolas 
não foram preparadas para lidar com seu papel de formadora e estruturadora social, seu ambiente ainda carece dos mecanismos e ferramentas necessários para que política seja feita, para que a criticidade seja estimulada. $\mathrm{Na}$ realidade existem tantas preocupações teoricamente maiores, que questões deste tipo acabam por ser completamente desconsideradas.

Mas, para exemplificar as consequências dessa interação, ou seja, da presença de uma distinta gama social de estudantes na rede pública explorando essa nova realidade e coexistindo com uma classe já acostumada com ela, pode-se citar um evento específico vivido por mim quando tive a oportunidade de visitar uma escola pública que não aquela onde estagiei - durante parte inicial da fase de observação do estágio. Conversando com a coordenadora da escola, descobri que, alguns anos antes daquele, havia sido implantado um sistema idealizado pela própria administração escolar objetivando a aquisição de fundos paralelos. Isso era feito a partir de um auxílio financeiro que era doado mensalmente pelos pais dos alunos que tinham condições para isso, cientes de que o dinheiro seria utilizado para obras voltadas a melhoria do prédio onde as aulas eram realizadas. Entretanto, ao questionar um dos funcionários para descobrir a razão deste projeto ter terminado, o mesmo nos informou que a decisão foi tomada porque os alunos começaram a criar conflitos entre eles, frequentemente, e passaram a se criticar ou satirizar utilizando muitas vezes o argumento de que os pais de um ajudavam a escola mais do que os pais do outro.

Esse fato isolado mostra o quanto a escola pública ainda carece de meios para intermediar questões relacionadas a este cunho monetário, por mais convidativo que seja pois essa participação efetiva dos pais, em uma ponte direta com as escolas, é justamente a mais rica confirmação do sujeito agente de sua educação. À renda das famílias e dos alunos sempre variou muito, e essa não deveria ser uma questão deixada de lado, ignorada ou evitada para não causar conflitos - muito pelo contrário, ela deveria ser trazida à tona, justamente para despertar uma maior consciência acerca de questões socioeconômicas no meio democrático da escola pública. Que os alunos menos favorecidos financeiramente não costumavam, há poucos anos, ocupar salas de aula das escolas públicas, já se sabe. 
Porém, agora, frente a essa nova condição ocasionada principalmente por uma crise geral no ensino como um todo, cabe a nós compreender tal problemática e repensar a respeito do ensino público como potencial transformador, e não válvula de escape ou sintoma de problemas do âmbito privado. Mas, para que isso seja possível, é necessário que profissionais capazes abram os olhos para esse novo problema, dentre todos os outros, e percebam que se trata de algo que deve ser tratado com o máximo cuidado e em suas medidas mais extremas.

Isto porque a miscigenação social e cultural é uma faca de dois gumes: pode ser extremamente positiva, se bem administrada. Colocar várias pessoas de realidades sociais distintas dentro do mesmo ambiente pode significar dar a oportunidade para que elas entendam, respeitem suas diferenças, e aprendam com elas. Mas é utópico acreditar que esse convívio saudável simplesmente acontece, da noite para o dia, em um país como este no qual vivemos - que respira desigualdade, mas expira preconceito de classe. Respeito é necessário, e ele já deixou de estar presente na escola pública há muito tempo, seja entre os colegas, entre alunos e professores e/ou vice-versa. Esse novo núcleo estudantil que começa a aparecer dentro dessa realidade só coloca mais um peso numa bagagem que já vinha cheia - o que pode ser negativo por tornar ainda mais impossível carregarmos esse peso com eficiência, mas também positivo por evidenciar a necessidade de arrebentar essa bagagem de uma vez. Afinal, já passou da hora de serem consideradas questões sociais dentro das instituições de ensino. Vivemos num mundo e, principalmente, num país onde não se podem separar as ramificações sociais de forma instrumental, e considerar o convívio saudável entre colegas de classe pedagogicamente inócuo, defendendo que o que de fato importa é o conteúdo ensinado para eles. Não é assim que a banda toca, não é assim que os interesses e necessidades dos alunos funcionam, e não é ignorando esses interesses e necessidades que os alunos "funcionarão". 


\section{Discussão: indivíduos "educados devidamente"}

Partindo dos dados coletados e de nossa análise podemos chegar às seguintes reflexões: Escolas são ocupadas por alunos e funcionários, e o ensino nelas praticado, em primazia, coordenado por um professor - ainda que não mais como o possuidor único do saber institucionalizado. Assim, minha discussão não pode deixar de lado o desafio da profissão professor. Sabemos que o desenvolvimento de uma nação depende, primeiramente, da educação; e, por esse motivo, toda esta responsabilidade é colocada sobre o professor. Mas por que esse profissional de tanto valor não é, como todos sabemos, devidamente valorizado e respeitado? "Exercer a profissão de professor na maioria das vezes é um ato de extrema valentia e determinação, tanto nas escolas públicas como nas privadas" (FREITAS, 2010, p. 39). A fala de Freitas (2010) se deve ao fato de que há uma grande incidência de violência contra os professores, seja ela verbal, ou até mesmo física. Isso demonstra a atual situação do professor no nosso país, seja no contexto público ou privado, já que, em qualquer um, a desvalorização é a mesma. O professor, por exemplo, costuma não ter autonomia suficiente para aprovar ou reprovar um aluno. O sistema público educacional, principalmente, determina previamente o percentual de aprovação, e isso deve ser cumprido, pois todo o meio está ligado ao FMI, UNESCO. Esse percentual determina a liberação de créditos para a educação.

$\mathrm{Na}$ esfera particular, ainda que a sombra das prescrições públicas seja menos incisiva, arrisco dizer que ocorre a mesma falta de "voz" por parte do professor, pois se os pais pagam uma alta mensalidade durante todo o ano, eles não querem ver os filhos reprovados. Novamente a carga está sobre o professor, sempre subalterno - ora pressionado pelo estado que age em conformidade com os interesses de mercado, ora pressionado pelos pais ou responsáveis, que fazem o mesmo ainda que, muitas vezes, sem tomar ciência disso. Esta situação nos mostra não só que a educação no Brasil se tornou um comércio - o Governo não quer perder os investimentos e o setor particular, as receitas - mas também explica em parte porque os professores acabam se tornando muitas vezes céticos com relação à sua capacidade de fazer seu trabalho de forma digna e eficiente. Profissão essencial 
e profundamente honrosa, a cada dia os professores se tornam mais passíveis de síndromes e patologias como a depressão ou crise do pânico, porque, no fundo, muitas vezes, sua importância é representada apenas pelas propagandas, no mais raso nível discursivo. Esse que é apenas mais um problema relativo ao descaso quanto à educação em todas as esferas, e coloca uma séria questão em pauta: o sentimento do professor em relação ao seu trabalho. Obviamente para que uma aula seja realizada de forma efetiva há a necessidade de uma relação saudável e respeitosa entre professor e aluno; mas isso se torna, a cada dia, mais difícil de se alcançar. Professores são considerados operadores de uma maquinaria produtivista, sendo os alunos as máquinas, e a lógica é apenas que tudo esteja operante, sem questionamentos, sem reflexões, sem que a "linha de produção" seja colocada em cheque.

A educação institucionalizada, especialmente nos últimos cento e cinquenta anos, serviu - no seu todo - o propósito de não só fornecer os conhecimentos e o pessoal necessário à maquinaria produtiva em expansão do sistema capitalista mas também o de gerar e transmitir um quadro de valores que legitima os interesses dominantes, como se não pudesse haver nenhum tipo de alternativa à gestão da sociedade ou na forma "internacionalizada" (i.e. aceite pelos indivíduos "educados" devidamente) ou num ambiente de dominação estrutural hierárquica e de subordinação reforçada implacavelmente. (MÉSZÁROS, 2008, p. 36)

Nessa dominação estrutural hierárquica o espaço onde está o professor fica abaixo de tudo, sendo seu papel formador, sua capacidade de proporcionar alternativas, abafado pelo desgaste de sua profissão. Arrisco dizer que a questão é talvez mais simples que imaginamos: a partir do momento que uma profissão é respeitada, o profissional que ocupa este ou aquele cargo também é respeitado. E vestir a condição de professor, no Brasil, não é uma tarefa que acarreta num retorno muito positivo. A sociedade brasileira, gradativamente se tornando, cada vez mais, tão corrupta quanto os políticos que elege, não qualifica o professor como alguém digno, alguém capaz; e achar que isso não tem consequências chega a ser irresponsável de nossa parte. Os alunos, em sua grande parte, não são ensinados 
a valorizar os professores, independente do fato de estudarem em escola pública ou particular, porque muitas vezes isso não foi uma preocupação dos seus pais, irmãos, colegas, ou até mesmo os próprios professores que na maior parte das vezes não valorizam a si mesmos - devido a uma condicionada autodepreciação. Professores são ensinados diariamente a aceitar a condição imposta por um padrão pré-determinado e suas tentativas de modificálo amplamente ignoradas, e é justamente aí que está a questão. Isso fica também perceptível quando levamos em conta os problemas pelos quais a escola pública passa há muitos anos, em paralelo com a carga emocional desgastada dos professores, cujo papel desempenhado nas escolas entra agora em pauta.

Além da tarefa de transferir conhecimento, ultimamente também está se fazendo necessário que os professores tomem frente de outras atividades que não deveriam ser de obrigação: "Eles passaram a ter funções que, na verdade, são de psicólogos, assistentes sociais, e até dos pais" (LEÃO, 2017, p. 85). O autor traça o perfil da escola pública brasileira e diz que além das dificuldades naturais dessa escola, também se agrava o fato de serem frequentadas, em sua maioria, por pessoas com estruturas familiares com alto grau de complexidade - pessoas essas que passam por alguma situação problemática em seu contexto de origem e, inevitavelmente, chegada. Dentro do perfil, portanto, também se aborda a questão disciplinar. Isso surge pela situação social, pois, se a própria sociedade está violenta, como é possível que a violência fique de fora dos muros da escola? Além disso, também a falta de perspectiva dos alunos reflete no comportamento estudantil. Vivemos num mundo extremamente competitivo, onde ser fracassado ou bem-sucedido depende apenas teoricamente exclusivamente do individual. Entretanto muitas vezes o aluno procura o estudo, se possível numa escola privada, para poder se superar, mas percebe que nem ele e nem a escola estão preparados para isso. Surge então a desilusão. "Esse não é um problema apenas da escola pública. Não tenho dúvida em dizer que $90 \%$ das escolas particulares são piores ou iguais às escolas públicas, sejam estaduais ou municipais" (LEÃO, 2017, p. 86), argumenta o autor, enfatizando, em seu discurso, as semelhanças escolas públicas e particulares. 
Todas essas questões obrigam os professores a "perderem" muito de suas funções. Com a obrigação de disponibilizar seu tempo conversando com os alunos questões que vão além de seu conhecimento e envergadura intelectiva, tentando melhorar o ambiente, e, muitas vezes, fazendo papel de pai, tutor ou responsável, ele acaba se sobrecarregando. A escola está sobrecarregada, e com isso, perde-se a chance de aplicar um conteúdo de forma reflexiva e coerente, o que representaria uma conquista para professores os alunos, mudando a partir disso o comportamento dos mesmos, que não se sentem interessados pelo que veem em sala de aula. Superações acontecem, devido ao trabalho digno e elogiável de muitos profissionais. Mas não seria justo depender disso, não é mesmo? A diferença para alguns pode ser feita por esforços particulares, mas, para revolucionar a educação no brasil, quem precisa se esforçar é a administração pública que muito pouco tem feito por ela - ao mesmo tempo que tanto cobra tais esforços particulares. Uma das formas para melhorar o ensino público seria investir de forma mais robusta. Segundo Leão (2017), seria necessário que pelo menos 4,5\% do PIB dedicados a educação para uma mudança clara de cenário. E o professor seria o primeiro a ganhar com isso. A valorização do profissional, como já indicado aqui, novamente surge como o primeiro passo para uma caminhada a uma escola pública de qualidade, e isso com certeza tem ligação direta com o suporte de seus agentes financeiros. Em termos de sistema, logo, é importante ter em mente a participação da nossa organização política e econômica:

As determinações abrangentes do capital afetam profundamente cada domínio singular com algum peso na educação, e de forma alguma apenas as instituições educacionais formais. Estas últimas estão estritamente integradas na totalidade dos processos sociais. Elas não podem funcionar adequadamente, exceto se estiverem em sintonia com as determinações educacionais abrangentes da sociedade como um todo. (MÉSZÁROS, 2008, p. 42)

A escola não funciona em um sistema onde o ensino tem pouca serventia; é preciso equilíbrio entre o ambiente escolar e aquele que o circunda, é preciso que o pensar se torne elogioso, ainda que, atualmente, seja a falta de pensamento nosso foco fundador. 
Nesse cenário, e por supostamente simbolizar tão pouco, o professor, infelizmente, está sendo submetido a uma evidente "exploração"; trabalhando no seu tempo que seria livre, e sem receber uma remuneração justa para tal. Pode-se citar, por exemplo, a quantidade de horas que o professor passa corrigindo provas; convocações que expropriam o tempo livre do professor; conselhos de classe em horário diferenciados e no qual é obrigatória a presença do professor; planejamento de aulas; tempo para deslocamento entre duas ou três escolas nas quais alguns professores precisam trabalhar para garantir um retorno financeiro digno o suficiente para o sustento de sua família. A direção burocrática das escolas impõe o cumprimento destas normas; e o professor, mesmo que muitas vezes por falta de escolha, acaba optando por aceitar. Outra grande crítica ao sistema administrativo das escolas é o grande número de seus administradores e coordenadores que não possuem nenhum tipo formação pedagógica, sendo que o trabalho dos mesmos acaba por se resumir somente atividades burocráticas. A própria pedagogia é vista de forma instrumentalizada, produtivista e burocrática, sendo os problemas inerentes a ela deixados a cargo do professor, para com eles ele lidar dentro da sala de aula.

\section{Considerações finais: uma "grave situação paralisante"}

Desrespeito e violência se tornam correntes, dar aula se torna uma profissão insalubre, arriscada, deprimente, e tudo isso prejudica não só alunos e professores, mas também a formação de novos profissionais. Isso já que os cursos de licenciatura vêm gradativamente apresentando estatísticas onde, “em uma sala de 40 alunos, apenas meia-dúzia opta por lecionar, bem como uma demanda baixíssima para os referidos cursos. Sem dizer que desta meia-dúzia, três deverão escolher escolas públicas como locais de trabalho" (BADKE; MARZARI, 2013, p. 54). A profissão “professor de escola pública” será extinta, caso caminhemos da maneira que o estamos fazendo. Ninguém se colocará à disposição para tal trabalho, sem salário ou condições condizentes. Assusta, nesse sentido, o profundo desconhecimento e desinteresse da realidade da escola pública e privada, por parte da população, que aceita as falaciosas propagandas de um estado que vê no professor público 
um inimigo, um vilão, um privilegiado - quando são os propagadores de tal discurso os que melhor (re)conhecem os privilégios que o estado pode de fato oferecer. Isto vem sendo alimentado por um preconceito que surge em consequência da falta de interesse de um sistema como um todo em despertar na sociedade admiração por esse ramo de trabalho tão digno, valorizado em países que viram na educação a propulsora de uma civilização mais democrática e desenvolvida - a citar os nórdicos, que poderíamos utilizar como modelos, e não como utopia. A educação formal se tornou, aqui, paralisante; máquina de aceitação e não de questionamento, de inserção numa lógica social ao invés de reposicionamento perante ela - para onde vamos com isso? Difícil, muito difícil saber.

Para terem a certeza, as instituições de educação formais são uma parte importante do sistema global da interiorização. Mas apenas uma parte. Quer os indivíduos participem ou não - durante menores ou maiores, mas sempre bastante limitados, números de anos - nas instituições de educação formais, eles devem ser induzidos a uma aceitação ativa (ou mais ou menos resignada) dos princípios reprodutivos orientadores dominantes da própria sociedade, adequados aos seu posto na ordem social, e de acordo com as tarefas reprodutivas que lhe foram assinaladas. Sob as condições da escravidão ou da servidão feudal, isto é, naturalmente, um problema bastante diferente daquele que deve prevalecer sob o capitalismo, mesmo quando os indivíduos trabalhadores formalmente não são de todo, ou são muito pouco, educados no sentido formal do termo. Todavia, ao interiorizarem as pressões exteriores omnipresentes, eles têm de adoptar as perspectivas globais da sociedade de consumo como os limites individuais inquestionáveis das suas próprias aspirações. Apenas a mais consciente ação coletiva pode destrinça-los desta grave situação paralisante. (MÉSZÁROS, 2008, p. 43)

Tão paralisante quanto a máxima que subestima a capacidade da escola pública de qualidade, enfatizando a superioridade do ensino privado - superioridade já não tão clara quanto costumava estar. De 2005 para cá, evidências que comprovam uma crescente crise inaceitável não só no desempenho da escola pública como também no da escola particular não param de surgir. Isto porque "a escola pública e escola particular perfazem, em grande medida, o mesmo imbróglio educacional, talvez para surpresa de muitos” (DEMO, 2006, p. 30). O desempenho da escola particular era, como regra, sensivelmente superior ao da 
escola pública, "para cujo êxito concorrem vários fatores, entre eles: gestão privada orientada para o mercado; professores não estáveis; pressão contra greves; pressão dos pais; funcionamento sistemático mais ou menos confiável; trato com alunos mais ricos etc." (DEMO, 2006, p. 31). Em função disso que aponta Demo (2006), em nenhum momento objetiva-se igualar essas duas realidades tão distintas. Mesmo porque o fato da escola particular ser gerida pela iniciativa privada, tendo como base uma pressão advinda dos pais dos alunos nela matriculados - e também em função mercado - não vai deixar de garantir que esta siga sempre em um nível mais financeiramente privilegiado (o que não é sinônimo de superior tendo em vista que, para educação, saúde e segurança, os sistemas públicos sempre se provaram funcionar de forma muito mais digna e democrática).

Há um choque de valores quando analisamos, por via de suposições hipotéticas, o que seria uma construção moral e intelectual condizente com o ideal e comparamos isto com o que de fato é cobrado do aluno dentro das instituições de ensino público e/ou particular. A deficiência na questão educacional que é tão essencial para o desenvolvimento de qualquer nação não pode ser negada, e não é uma tarefa fácil discutir a respeito de apenas um aspecto dentro de uma gama infinita de valores conturbados. Através de testes realizados em dez anos consecutivos, nas escolas públicas e particulares de todos os estados brasileiros, Demo (2006) faz uma leitura e discute o que os dados coletados significam de fato. A partir do que ele expõe é possível tecer comparações a nível dos estados entre desempenhos públicos e particulares. Na esfera pública, o desempenho em testes nacionais para avaliar a qualidade das escolas esteve em queda na década inteira, regredindo no período cerca de 35 pontos. A região que menos caiu foi o Sul, em 2005, com 4 pontos, ficando todas as outras entre 8 e 9 pontos. No ano seguinte, entretanto, ocorreram algumas quedas significativas tanto no setor público quanto privado. No público temos quedas de "33,9 pontos no Maranhão, 27 pontos no Rio de Janeiro, 24,3 pontos no Amazonas para ficarmos apenas com quedas superiores a 20 pontos" (DEMO, 2006, p. 62). Nisso vemos recuos inacreditáveis para um espaço de dois anos. Na escola particular, o desempenho também tem caído, ainda que em números menos significativos: "o norte caiu 1,5 pontos, o 
nordeste 3,2 , centro-oeste 8,3 , sudeste 9,3 , e sul 10,5 pontos. Há, pois, que reconhecer de um lado a superioridade da escola particular, mas, de outro, que ela também está contaminada por precariedades similares" (DEMO, 2006, p. 63). Aquilo que vinha gradativamente melhorando, a passos de formiga, caminha agora na direção inversa - e a educação pública e privada vem, no Brasil, vendo sua cova crescer em tamanho e proximidade.

O que os dados simbolizam é que apesar da mediocridade no meio educacional brasileiro ser geral, o setor público vê um concorrente se aproximando pouco a pouco de sua precariedade - um concorrente mais rico, estruturado e bem-sucedido, um concorrente que faz propaganda de si mesmo, e que se encaixa bem ao fenômeno neoliberal da contemporaneidade. O fato é que o brasileiro já está acostumado com a incapacidade educacional das escolas públicas as quais, de acordo com os dados trazidos pelo artigo em pauta, mostram uma estabilidade de queda anual de 0,4 pontos. Porém, ao ver que as escolas privadas apresentam um recuo de 2,2 pontos, a sociedade poderia estar em geral surpresa com os dados, uma decepção principalmente por parte daqueles que investem na instituição privada. Parte da busca familiar por condições socioeconômicas mais estáveis vê na escola privada uma aliada, bem como um foco - o sonho de colocar o filho naquela boa escola onde o pai ou responsável não pode estudar. Escolas particulares traduzem a chance de dar uma educação de qualidade, ainda que cara, para os filhos que merecem um futuro melhor. Infelizmente, manter os olhos fechados para a instituição pública fez dela escrava de valores capitalistas que não fizeram bem a ninguém. Vimos no vilão o salvador, e permitimos a ampla disseminação de um discurso crítico, privatista e preconceituoso com relação a escola pública - que, no fim das contas, será nossa única e melhor saída para esse cenário. Seria demais esperar que a sociedade tivesse se revoltado a tempo, já que:

Uma das funções principais da educação formal nas nossas sociedades é produzir tanta conformidade ou "consenso" quanto for capaz a partir de dentro e através dos seus próprios limites institucionalizados e legalmente sancionados. Esperar da sociedade mercantilizada a promulgação ativa ou mesmo a mera tolerância - de um mandato às suas insti- 
tuições de educação formal que as convidasse a abraçar plenamente a grande tarefa histórica do nosso tempo: ou seja, a tarefa de romper com a lógica do capital no interesse da sobrevivência humana, seria um milagre monumental. É por isso que, também no domínio educacional, os remédios "não podem ser formais; eles devem ser essenciais". Por outras palavras, eles devem abarcar a totalidade das práticas educacionais da sociedade estabelecida. (MÉSZÁROS, 2008, p. 45)

Para abraçar essa totalidade, é preciso desviar do maniqueísmo público/privado, romper com a lógica do capital no interesse da sobrevivência educacional, e colocar em cheque valores institucionalizados acerca do mundo escolar. Para a rede pública o constrangimento desta generalização que a diminui perante a esfera privada já foi de certa forma absorvido, mas para a rede particular essa democratização da mediocridade acaba sendo bastante incômoda, em especial no ensino fundamental, onde ela é capaz de trazer para si apenas $10 \%$ dos alunos do país. Neste sentido, a qualidade da escola particular como um todo prova deixar de condizer com sua fama, expectativa e custo, principalmente seguindo essa linha instrumentalizada - que vê no sujeito a peça de um maquinário, não uma mente em potencial. Isso já que, se observarmos as pedagogias oferecidas no país, as instituições particulares não oferecem propostas alternativas: “Ao contrário, aprofundam ainda mais o instrucionismo, por conta do mercantilismo muitas vezes dominante: os cursos são encurtados ao mínimo possível legalmente, somente se dão aulas, tudo se copia, nada se cria” (DEMO, 2006, p. 71). Este sistema de (de)formação despeja nas escolas professores muitas vezes desmotivados e despreparados, não profissionalizados, que muitas vezes não conseguem dar conta de suas tarefas. "De fato, no Brasil ainda não se distingue aula e aprendizagem. É dogma docente que aprender é escutar aula. Esta visão não se sustenta em nenhuma teoria e prática minimamente adequada, mas faz parte do imaginário secular do professor brasileiro" (DEMO, 2006, p. 72). Esta é a verdadeira vala comum. Os dados sugerem no mínimo isso: continuando como está não vamos a lugar nenhum. O que fazemos em sala de aula não tem sentido como condição e motivação ao bom desempenho escolar. 
Bem articulada é a reflexão de Demo (2006) sobre a conturbação de valores educacionais, criticando a proposta pragmática das instituições de ensino, onde se formam eleitores, e não leitores. Por interesse do governo, o aluno não é ensinado a interpretar o mundo de uma forma ampla e abstrata, mas a focar e desenvolver sua linha de pensamento a partir de uma visão limitada e fechada, alimentada por doutrinas construtoras de um sujeito socialmente insignificante. Escolas públicas e particulares, através de projetos "revolucionários" muitas vezes paliativos e que dificilmente saem do papel, se tornam, assim, mais uma farsa social. Obviamente existem ideias e mentes competentes o suficiente para repensar a respeito deste aspecto de forma corriqueira, com o intuito de "desmediocriozar" a condição educacional brasileira. Infelizmente, muitas vezes, o efeito acaba sendo o oposto do esperado, como já apontado, ou acaba servindo como "exemplo a ser seguido" ao invés de prática institucional para transformação sistemática da lógica educativa. No retrocesso escolar geral, em ambos os âmbitos, vemos o Brasil caminhar para um rumo perigoso, para o qual não há poção mágica. Demo (2006) correlaciona bem os dados coletados com o intuito de explicar e exemplificar a falta de preparo da escola brasileira, nunca defendendo que a queda em qualidade da escola particular acarreta num avanço do setor público, mesmo porque essa seria uma relação sem fundamento. Há uma crise crescente, para onde se quer que olhe, a qual só mostra o quanto a necessidade de aprimoramento substancial na educação brasileira é iminente.

\title{
ENGLISH CLASS AND THE DISASSEMBLY OF EDUCATION AS A POLITICAL PRACTICE: A SOCIAL ALIENATION PROJECT
}

\begin{abstract}
This article aims at reflecting upon some educational issues drawn in parallel with social praxis. More specifically, the idea is to discuss aspects and implications of students' social reality and practice in state schools taking into account contemporary anxieties on the matter. The data analysed has been collected in the city of Maringa-PR, during 2009, as part of my compulsory undergraduate supervised teaching practice took place - regarding the observation of school surroundings as well as of the classes themselves. Focusing on this social aspect of educational school practice, the main theoretical framework for data analysis is brought by István Mészáros in Education beyond Capital (2005). The non-conclusive results pinpoint an alarming scenery: if in the private sector education
\end{abstract}


has for long been turned into a commodity and students into mere clients, the public one has been gradually redirected to analogous paths, in many ways.

KEYWORDS: Experience report. Marx. State school.

\section{REFÊRENCIAS}

BADKE, Mariluza; MARZARI, Gabriela. Ensino e aprendizagem de língua inglesa em escolas públicas. Pesquisas em discurso pedagógico (UNIFRA), n. 2, v. 1, 2013. pp. 50-71

CAMPOS, Geórgia. [S.I], 19 de jun. 2008. Disponível em < http://e-educador.com/index.php/artigos-mainmenu-100/2020 >. Acesso em: 14 out. 2009.

DEMO, Pedro. Escola pública e escola particular: semelhanças de dois imbróglios educacionais. São Paulo: Parábola, 2006.

FREITAS, Eduardo. A dura realidade do professor. Brasil Escola: edição especial. São Paulo: Abril, 2010. p. 37-43

LEÃO, Roberto. A escola pública brasileira: Uma realidade dura. Revista do Instituto Humanitas, n. 4, v. 16, 2017. pp. 77-89

MARX, Karl; ENGELS, Friedrich. 1847. Manifesto Comunista. In: JINKINGS, Ivana; SADER, Emir. As armas da crítica: antologia do pensamento de esquerda: Clássicos. Trad. Álvaro Pina. São Paulo: Boitempo, 2012, p. 15-34

MÉSZÁROS, István. 2005. A educação para além do capital. Trad. Isa Tavares. São Paulo: Boitempo, 2008. 